\title{
Subsidizing Innovation and Production
}

\author{
Gamal Atallah ${ }^{\mathrm{a}}$ \\ ${ }^{a}$ Department of Economics, University of Ottawa, 120 University, Ottawa (Ontario), K1N 6N5, Canada \\ $\bowtie$ gatallah@uottawa.ca
}

\begin{abstract}
This paper studies the interaction between production subsidies and innovation subsidies. We develop a model which allows us to calculate the socially optimal subsidies (and how they vary with changes in the economic environment), and to understand how firms react to each type of subsidy. In a three-stage game, the government chooses production and innovation subsidies in the first stage to maximize welfare in the presence of a shadow cost of public funds; two firms invest in cost-reducing $R \& D$ in the second stage; and the two firms compete in quantities in the last stage. We find that production subsidies crowd out innovation. On the other hand, providing a production subsidy reduces the cost of the innovation subsidy, and vice versa. The optimal production subsidy either increases monotonically with spillovers, or is U-shaped with respect to spillovers, depending on exogenous parameters. The innovation subsidy is increasing in spillovers. The production subsidy is higher for very low spillovers, while the innovation subsidy is higher for moderate/high spillovers. In equilibrium, because of the innovation subsidy, R\&D increases with spillovers, and so does welfare. We also consider the case of a financially constrained government, as well as the case of a uniform subsidy to production and innovation costs.
\end{abstract}

Article History: Received: October 262018 / Revised: May 62019 / Accepted: May 82019

Keywords: Production subsidy; Input subsidy; Output subsidy; Innovation subsidy; R\&D subsidy; R\&D; R\&D spillovers; Process innovation.

JEL Classification: D43, L50, O38

\section{Acknowledgements}

I would like to thank two anonymous referees, Unni Pillai, Gabriel Rodríguez, Roger Ware, participants to the International Industrial Organization Conference, the conference of the Canadian Economics Association, the EARIE conference, the conference of La Société canadienne de science économique, as well as seminar participants at the University of Ottawa for their useful comments and suggestions which have contributed to improve the paper. 


\section{Introduction}

Governments in both developed and developing countries offer substantial subsidies/tax credits to privately owned firms. For example, in OECD countries governments finance between 8 and $10 \%$ of R\&D spending by firms (García-Quevedo, 2004). In Europe, sugar and dairy processing firms receive large amounts of farm subsidies (Lawrence, 2010). The U.S. and the EU regularly trade charges of subsidizing their domestic aircraft industry ${ }^{1}$. Large Chinese companies also receive substantial government subsidies (Davis, 2013), and those subsidies increase firm value (Lee et al., 2014).

Governments use subsidies as an industrial policy tool to pick winners, to give an advantage to a firm over its (sometimes foreign) competitors, to promote exports, to pursue social policy or environmental objectives, to compensate for market imperfections, or in response to lobbying/capture considerations, for example. Financial support can take different forms: grants, investment subsidies, export subsidies, wage subsidies, R\&D subsidies, agricultural price support programs, fuel subsidies in many developing countries, subsidies to consumers when they buy certain products (which also benefit the producers of those products by increasing demand), government procurement, market price support, interest free loans, guarantees to banks, support to ailing firms, tax-deductible borrowing costs, etc. Such subsidies often go against WTO rules, yet they remain widespread for economic and political considerations. Studwell (2013) shows that subsidies, along with other policies, played an important role in the economic development of Asian countries such as Japan, South Korea, and Taiwan.

Yet, most economic models assume that firms behave without explicit government support, except in the presence of some specific externalities or market failures (like underinvestment in innovation or green energy/technology related subsidies). Examples of papers having modelled innovation subsidies only are Petrakis and Poyago-Theotoky (2002), Lahiri and Ono (1999), and Hall and Laincz (2012). Most studies find that the optimal innovation subsidy increases with R\&D spillovers. Another common finding is that more efficient firms should be subsidized more heavily.

There is no agreement in the empirical literature on whether, or by how much, public subsidies to innovation increase private R\&D (see Zúñiga-Vicente et al. (2014) who review a large number of empirical studies on this topic). Although a substantial number of studies conclude that private R\&D responds positively to government support (Guellec and van Pottelsberghe de la Potterie, 2003). For a review of the empirical literature on this topic, see Atallah (2014).

A few papers have studied the interaction between production and innovation subsidies. Kesavayuth and Zikos (2013) study the welfare effects of an R\&D subsidy versus an output subsidy in a mixed duopoly. They find that the R\&D subsidy is more socially beneficial when spillovers are high, whereas the output subsidy is superior when spillovers are low. However, in their model the government has to choose between the two subsidies, whereas in our framework the government is free to offer both types of subsidies. Moreover, they do not attempt to calculate the socially optimal level of either subsidy.

\footnotetext{
${ }^{1}$ See Gössling et al. (2017) for a study of the various forms of subsidies to the aviation sector.
} 
Leahy and Neary (1997) develop a model with output and innovation subsidies. They find that in the absence of spillovers under Cournot competition (and assuming the government can commit to the optimal output subsidy), R\&D should be taxed, as firms over-invest in $R \& D^{2}$. Whereas under Bertrand competition, R\&D should always be subsidized. When the government cannot commit to the output subsidy (and assuming the output subsidy is a strategic complement to $R \& D$ ), the optimal $R \& D$ subsidy is lower than with commitment, and may be positive or negative, with or without R\&D cooperation.

Lee et al. (2017) study R\&D and output subsidies in a mixed duopoly. They focus on privatization, and find that welfare is higher under an output subsidy than under an R\&D subsidy. Moreover, compared to the $\mathrm{R} \& \mathrm{D}$ subsidy, the government has a higher incentive to privatize under the output subsidy. They find that the optimal rate of $R \& D$ subsidy is negative, and increases with the degree of privatization. However, they do not consider R\&D spillovers, and this probably explains in part their negative $R \& D$ subsidy.

Zikos (2007) considers a mixed duopoly with output and R\&D subsidies. He allows for the possibility of Stackelberg competition, and for privatization. He finds that the optimal output subsidy is constant. Furthermore, R\&D should be taxed, and this tax varies with privatization and the order of play. However, his model does not take into account R\&D spillovers.

Whereas Leahy and Neary (1997) (as well as Kesavayuth and Zikos, 2013) use an output subsidy, we use an input subsidy. While an output subsidy is related to production volume, an input subsidy aims at covering a portion of the cost of some or all inputs. The two subsidies are not equivalent. For example, Parish and Mclaren (1982) show, using a theoretical model, that in some cases the input subsidy may be more cost effective to the government than an output subsidy. Using data from Bangladesh, Nehring (1994) finds that the output subsidy (price support to agricultural products) is more effective than the input subsidy (on fertilizers). Moreover, in the previously mentioned studies there is no shadow cost of public funds, which we incorporate here.

In this paper we classify subsidies into two main types: a production subsidy, which is proportional to a firm's production costs; and an innovation subsidy, which is proportional to a firm's innovation costs. We develop a model which allows us to calculate the socially optimal subsidies (and how they vary with changes in the economic environment), and to understand how firms react to each type of subsidy.

In a three-stage game, the government chooses production and innovation subsidies in the first stage to maximize welfare in the presence of a shadow cost of public funds; two firms invest in cost-reducing R\&D in the second stage; and the two firms compete in quantities in the last stage. We calculate the optimal subsidies, and analyze how they vary with spillovers and other model parameters. We explore the effect of providing one type of subsidy on the cost of the other subsidy. We also study strategic interaction between production and innovation subsidies. We then compute the subsidies provided by a government facing a budget constraint. Finally, we study the case where the government has to choose a single subsidy rate that applies to both production and innovation costs.

\footnotetext{
${ }^{2}$ A similar result was obtained by Petrakis and Poyago-Theotoky (2002) in their study of environmental R\&D.
} 
We find that production subsidies crowd out innovation, since they reduce the gain for firms from investing in $\mathrm{R} \& \mathrm{D}$. On the other hand, providing a production subsidy reduces the cost of the innovation subsidy, and vice versa. We find that the optimal production subsidy either increases monotonically with spillovers, or is U-shaped with respect to spillovers, depending on model parameters. The innovation subsidy is increasing in spillovers. The production subsidy is higher for very low spillovers, while the innovation subsidy is higher for moderate/high spillovers. In equilibrium, because of the innovation subsidy, R\&D increases with spillovers. Consumer surplus and profits are U-shaped with respect to spillovers when the production subsidy is Ushaped with respect to spillovers, and increase monotonically with spillovers when the production subsidy always increases with spillovers. Welfare always increases with spillovers. We also find that subsidies are more likely to be strategic complements when the production subsidy is low, when the innovation subsidy is high, and when spillovers are low. Optimal subsidies increase with research costs and with the slope of inverse demand, and have an inverted-U shape with respect to initial costs and demand height. A financially constrained government reduces production subsidies much more than innovation subsidies, except for very low spillovers. Surprisingly, the optimal uniform subsidy is not intermediate between the optimal production and innovation subsidies: rather, the uniform subsidy is lower (higher) than both production and innovation subsidies for low (high) spillovers. Moreover, the uniform subsidy induces a negative relationship between R\&D and spillovers.

One objective of the paper is to make specific policy recommendations. The results of the model can serve as a guide to industrial and innovation policy. The model suggests that policymakers should calculate the optimal production and innovation subsidies jointly: the optimal level of one depends on the optimal level of the other. In addition, the model identifies several important criteria which should be taken into account when calculating those subsidies: the level of R\&D spillovers (related to intellectual property rights protection), production costs, the price elasticity of demand, and the shadow cost of public funds. The model shows how the optimal subsidies have a negative relationship with intellectual property rights. The results also point out that production subsidies can crowd out innovation, an effect which is not taken into account in the theoretical or empirical literature. Moreover, the model recommends that a government facing serious financial constraints should focus on subsidizing innovation, and spend much less on subsidizing production. Finally, the results point to an unexpected synergy between the two types of subsidies, in that each type of subsidy reduces the cost to the government of providing the other subsidy.

These policies are different from what is used in several countries. Thus the paper contributes to industrial policy and innovation policy by providing some clear results which can be used as guidelines for specific countries and industries. Moreover, the numerical nature of the model makes it easy to adapt it to specific industries with particular characteristics.

In section 2 , we present the model and derive equilibrium output, $R \& D$ and subsidies. In section 3, we study the effect of spillovers on optimal subsidies. In section 4, the effects of subsidy rates on subsidy costs are analyzed. Section 5 studies the strategic interaction between innovation and production subsidies. In section 6, we examine the effect of demand and cost

\section{(is) PUCP}


parameters on optimal subsidies. In section 7 , we consider the effect of financial constraints by varying the shadow cost of public funds, and then by introducing a budget constraint. Section 8 examines the case where the government uses a uniform rate to subsidize production and innovation. Section 9 concludes.

\section{The Model}

Two identical firms producing a homogeneous good invest in cost-reducing R\&D before competing à la Cournot. Before firms make any decisions, a social planner chooses the subsidy rates for production and innovation costs to maximize welfare. The social planner uses the two instruments to control output and innovation. Demand is given by $p\left(y_{1}, y_{2}\right)=a-b\left(y_{1}+y_{2}\right)$. Unit costs are

$$
c_{i}\left(x_{i}, x_{j}\right)=\alpha-x_{i}-\beta x_{j}, \quad i, j=1,2, \quad i \neq j,
$$

where $c$ is final marginal cost, $\alpha$ is initial marginal cost (before cost-reducing $R \& D$ ), $x$ is per firm $R \& D$ output, and $\beta \in[0,1]$ is the $R \& D$ spillover rate. Parameter values are assumed to be such that in equilibrium, $c>0$. Profit is given by

$$
\pi_{i}=\left(p-\left(1-s_{c}\right) c_{i}\right) y_{i}-\left(1-s_{x}\right) \frac{\gamma}{2} x_{i}^{2}, \quad i=1,2,
$$

where $s_{c} \in[0,1]$ is the subsidy to production costs, $s_{x} \in[0,1]$ is the subsidy to innovation costs, and $\gamma$ is an R\&D cost parameter inversely related to the efficiency of R\&D. We call $\left(1-s_{c}\right) c_{i}$ the effective marginal cost of firm $i$.

Consumer surplus is given by

$$
C S=\frac{b}{2}\left(y_{1}+y_{2}\right)^{2}
$$

Let industry profits be given by $\Pi=\pi_{1}+\pi_{2}$. Welfare is

$$
W=C S+\Pi-(1+\lambda)\left[s_{c}\left(c_{1} y_{1}+c_{2} y_{2}\right)+s_{x} \frac{\gamma}{2}\left(x_{1}^{2}+x_{2}^{2}\right)\right]
$$

where $\lambda>0$ is the shadow cost of public funds. The only reason the government subsidizes output in this model is firms' market power: by reducing the effective marginal cost firms face, price is reduced and output is expanded. On the other hand, the need to subsidize innovation is well understood.

It is clear that for very low values of $\lambda$, it will be optimal to subsidize $100 \%$ of production and innovation costs (or at least the government will choose high enough subsidies to induce the socially optimal price, output and innovation levels). And for sufficiently high values of $\lambda$, the government will prefer not to provide any subsidy to either production or innovation activities. To focus on an interior solution, we choose the value of $\lambda$ such that the optimal values of $s_{c}$ and $s_{x}$ lie strictly between 0 and 1 . We will have more to say about corner solutions when we study optimal subsidies for a financially constrained government in section 7 .

In the first stage, the government chooses $s_{c}$ and $s_{x}$. In the second stage, firms choose R\&D investments. In the third and last stage, firms compete in output. 
Solving the third stage yields Cournot quantities as a function of $R \& D$ outputs and the production subsidy:

$$
y_{i}\left(x_{i}, x_{j}\right)=\frac{\alpha-\left(1-s_{c}\right)\left[\alpha-(2-\beta) x_{i}+(1-2 \beta) x_{j}\right]}{3 b}, \quad i, j=1,2, \quad i \neq j .
$$

Substituting (5) into the profit functions (2) and letting each firm choose its R\&D to maximize its profit yields R\&D output as a function of the subsidy rates (and other parameters):

$$
x_{i}\left(s_{c}, s_{x}\right) \quad i=1,2 .
$$

The analytical solutions of (6) are quite cumbersome (7 lines of Mathematica output) and are not shown. As firms are identical ex ante, the equilibrium is symmetric. Substituting (6) into welfare (4) and letting the social planner choose $s_{c}$ and $s_{x}$ to maximize welfare yields the optimal subsidies $^{3}$

$$
s_{c}(a, b, \alpha, \beta, \gamma, \lambda), \quad s_{x}(a, b, \alpha, \beta, \gamma, \lambda) .
$$

The analytical complexity of the model makes it impossible to derive a closed-form solution without first assigning numerical values to the parameters $a, b, \alpha, \beta, \gamma$ and $\lambda$. We use the following numerical configuration as the "base" configuration: $a=1000, b=1, \alpha=50, \beta=0.4, \gamma=60$, and $\lambda=0.27^{4}$. Given that the model is not tailored to any particular industry, there is no particular economic significance associated with these numerical values; all what is required is that in the base configuration and as parameters change when performing numerical simulations, all equilibrium quantities, prices, and $R \& D$ investments remain strictly positive, thus focusing on interior solutions ${ }^{5}$.

To study the effects of any parameter on the equilibrium, we fix all other parameters following the base configuration, and allow that parameter to vary. Alternative numerical configurations have been used, and the results remain unchanged qualitatively. All results will be illustrated graphically (sometimes in combination with tables), and evaluated at discrete values of the parameter under study.

\footnotetext{
${ }^{3}$ While we are unable to solve explicitly for the optimal values of $s_{c}$ and $s_{x}$ by solving the f.o.c. (the f.o.c. w.r.t. $s_{c}$ has about 4500 lines of Mathematica output), we are able to calculate the optimal values of $s_{c}$ and $s_{x}$, after giving numerical values to all other parameters, using the ArgMax command in Mathematica. A Mathematica file containing the model, analytical results, and the commands necessary to generate the numerical simulation results is available from the author upon request.

${ }^{4}$ The model becomes unstable at $\beta=0.5$ (some variables become negative, etc.). For that reason, we use $\beta=0.4 \overline{9}$ instead of $\beta=0.5$. The same thing happens when $s_{c}$ or $s_{x}$ take the value of 1 ; in that case we attribute to them the value $0.9 \overline{9}$.

${ }^{5}$ The advantage of using numerical simulations is that they allow us to derive results which would be impossible to obtain analytically. It is not possible to derive these results with more general functions. With more general functions, we can answer a limited set of questions. Using specific functions, we can obtain more specific results. We lose in generality, but we obtain results which are difficult or impossible to derive at the most general level. Some of the modeling limitations found in other studies, like allowing the government to provide only one type of subsidy, or not calculating the socially optimal subsidies, are avoided in this paper, thanks to the use of numerical simulations.
} 


\section{Effect of R\&D Spillovers on Optimal Production and Innovation Subsidies}

In this section we analyze the effect of spillovers on optimal subsidies, on the marginal benefits and costs of subsidies, and on consumer surplus, profits and welfare. Before considering the effect of spillovers, first we note that R\&D decreases with $s_{c}$. To see that, we fix other parameter values, we fix $s_{x}$ at 0.2 and $\beta$ at 0.4 (the specific values of these variables are irrelevant for the relationship), and plot $x$ as a function of $s_{c}$ (see Figure 1$)^{6}$. Firms respond to an increase in the production subsidy by reducing their investments in innovation. An increase in $s_{c}$ induces four effects on the innovation incentives of firm $i$. First, a reduction in the effective marginal cost $\left(1-s_{c}\right) c_{i}$, reducing the incentives to innovate; in the limit, if $100 \%$ of production costs were subsidized, firms would have no incentive at all to invest in innovation. Second, a reduction in the effective marginal cost of the competitor; this reduces the incentives of firm $i$ to invest in R\&D. Third, an increase in output $y_{i}$ (because of the reduction in the effective marginal cost of firm $i$ ); this effect increases the incentives to innovate. Fourth, a reduction in $x_{j}$; this increases (decreases) the optimal $x_{i}$ for firm $i$ for low (high) spillovers. The sum of the negative effects always dominates the sum of the positive effects; hence, production subsidies crowd out innovative activities.

Regularity $1 . \frac{\partial x}{\partial s_{c}}<0$

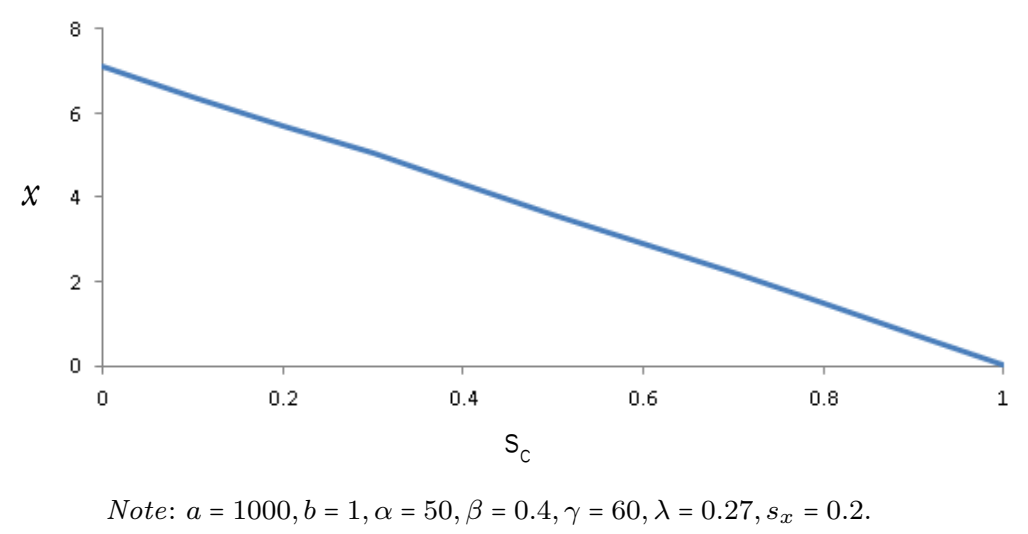

Figure 1. R\&D as a function of the production subsidy.

Consider now the effect of $\beta$ on the optimal subsidies. We have the following result.

Regularity 2. The optimal production subsidy either i) increases monotonically with spillovers, or ii) is U-shaped with respect to spillovers. The optimal innovation subsidy increases with $\beta$.

The following tables illustrate the results of Regularity 2 for different numerical configurations.

Table 1a is consistent with case (i) of Regularity 2, while tables $1 \mathrm{~b}$ to $1 \mathrm{e}$ are consistent with case (ii). Consider first Table 1a. The following figure illustrates the optimal subsidies described in Table $1 \mathrm{a}$ as a function of spillovers.

\footnotetext{
${ }^{6}$ On figures 1, 7 and 8, subsidies are exogenous. On all other figures, subsidies are endogenous, even when they do not appear on the vertical axis.
} 
Table 1

Effect of spillovers on subsidies.

(a) Configuration 1: $a=1000, b=1, \alpha=50, \gamma=60, \lambda=0.27$.

\begin{tabular}{|c|c|c|c|c|c|c|c|c|c|c|c|}
\hline$\beta$ & 0 & 0.1 & 0.2 & 0.3 & 0.4 & 0.5 & 0.6 & 0.7 & 0.8 & 0.9 & 1 \\
\hline$s_{c}$ & 0.7076 & 0.6980 & 0.6913 & 0.6873 & 0.6864 & 0.6886 & 0.6943 & 0.7041 & 0.7185 & 0.7387 & 0.7661 \\
\hline$s_{x}$ & 0.6275 & 0.6666 & 0.7029 & 0.7369 & 0.7686 & 0.7984 & 0.8263 & 0.8526 & 0.8775 & 0.9009 & 0.9232 \\
\hline
\end{tabular}

(b) Configuration 2: $a=1500, b=3, \alpha=100, \gamma=120, \lambda=0.28$.

\begin{tabular}{|c|c|c|c|c|c|c|c|c|c|c|c|}
\hline$\beta$ & 0 & 0.1 & 0.2 & 0.3 & 0.4 & 0.5 & 0.6 & 0.7 & 0.8 & 0.9 & 1 \\
\hline$s_{c}$ & 0.5746 & 0.5753 & 0.5766 & 0.5787 & 0.5814 & 0.5849 & 0.5890 & 0.5941 & 0.5998 & 0.6065 & 0.6141 \\
\hline$s_{x}$ & 0.4666 & 0.5364 & 0.5959 & 0.6474 & 0.6923 & 0.7318 & 0.7668 & 0.7979 & 0.8258 & 0.8508 & 0.8733 \\
\hline
\end{tabular}

(c) Configuration 3: $a=800, b=0.5, \alpha=200, \gamma=90, \lambda=0.26$.

\begin{tabular}{|c|c|c|c|c|c|c|c|c|c|c|c|}
\hline$\beta$ & 0 & 0.1 & 0.2 & 0.3 & 0.4 & 0.5 & 0.6 & 0.7 & 0.8 & 0.9 & 1 \\
\hline$s_{c}$ & 0.1823 & 0.1832 & 0.1843 & 0.1856 & 0.1871 & 0.1888 & 0.1907 & 0.1930 & 0.1955 & 0.1982 & 0.2013 \\
\hline$s_{x}$ & 0.0227 & 0.1451 & 0.2498 & 0.3405 & 0.4197 & 0.4894 & 0.5513 & 0.6066 & 0.6562 & 0.7010 & 0.7417 \\
\hline
\end{tabular}

(d) Configuration 4: $a=500, b=1.5, \alpha=40, \gamma=30, \lambda=0.25$.

\begin{tabular}{|c|c|c|c|c|c|c|c|c|c|c|c|}
\hline$\beta$ & 0 & 0.1 & 0.2 & 0.3 & 0.4 & 0.5 & 0.6 & 0.7 & 0.8 & 0.9 & 1 \\
\hline$s_{c}$ & 0.7173 & 0.7214 & 0.7283 & 0.7381 & 0.7510 & 0.7677 & 0.7885 & 0.8142 & 0.8458 & 0.8846 & 0.9324 \\
\hline$s_{x}$ & 0.6381 & 0.6904 & 0.7366 & 0.7777 & 0.8146 & 0.8481 & 0.8786 & 0.9065 & 0.9321 & 0.9558 & 0.9775 \\
\hline
\end{tabular}

(e) Configuration 5: $a=3000, b=1, \alpha=500, \gamma=600, \lambda=0.23$.

\begin{tabular}{|c|c|c|c|c|c|c|c|c|c|c|c|}
\hline$\beta$ & 0 & 0.1 & 0.2 & 0.3 & 0.4 & 0.5 & 0.6 & 0.7 & 0.8 & 0.9 & 1 \\
\hline$s_{c}$ & 0.4582 & 0.4585 & 0.4588 & 0.4592 & 0.4596 & 0.4601 & 0.4606 & 0.4612 & 0.4619 & 0.4626 & 0.4633 \\
\hline$s_{x}$ & 0.3234 & 0.4109 & 0.4850 & 0.5485 & 0.6036 & 0.6518 & 0.6944 & 0.7323 & 0.7661 & 0.7966 & 0.8241 \\
\hline
\end{tabular}

To understand these relationships, we write the f.o.c. determining $s_{c}$ and $s_{x}$. Let $\theta_{c}$ represent the total cost of the production subsidy to the government:

$$
\theta_{c}=(1+\lambda) s_{c}\left(c_{1} y_{1}+c_{2} y_{2}\right)
$$

and let $\theta_{x}$ represent the total cost of the innovation subsidy:

$$
\theta_{x}=(1+\lambda) s_{c} \frac{\gamma}{2}\left(x_{1}^{2}+x_{2}^{2}\right) .
$$

Then we can write the f.o.c. for the choice of $s_{c}$ as

$$
\frac{\partial W}{\partial s_{c}}=\frac{\partial C S}{\partial s_{c}}+\frac{\partial \Pi}{\partial s_{c}}-\frac{\partial \theta_{c}}{\partial s_{c}}-\frac{\partial \theta_{x}}{\partial s_{c}}=0 .
$$

Similarly, we can write the f.o.c. for the choice of $s_{x}$ as

$$
\frac{\partial W}{\partial s_{x}}=\frac{\partial C S}{\partial s_{x}}+\frac{\partial \Pi}{\partial s_{x}}-\frac{\partial \theta_{c}}{\partial s_{x}}-\frac{\partial \theta_{x}}{\partial s_{x}}=0 .
$$

As these expressions are hopelessly complicated analytically, we analyze them graphically, with all variables (including subsidies) taking their equilibrium values. 


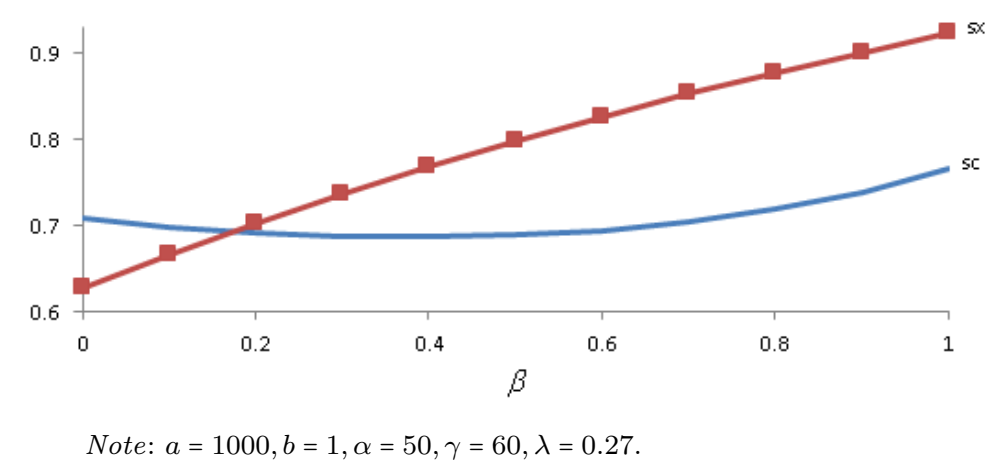

Figure 2. Effect of spillovers on subsidies.

Figure 3 shows the four terms composing the f.o.c. for $s_{c}$ from equation (10). The sum of the two marginal benefits curves minus the sum of the two marginal cost curves always yields zero. We explain the relationship between the four terms and spillovers as follows:

1) and 2) The marginal benefits of $s_{c}$ to consumers and firms decrease with spillovers. As spillovers increase, costs decrease (because R\&D increases), and a given increase in $s_{c}$ leads to a smaller reduction in costs (for firms) and in prices (for consumers) in dollar terms.

3) The marginal effect of $s_{c}$ on $\theta_{c}$ increases with spillovers (even when $s_{c}$ itself decreases with spillovers ${ }^{7}$, which occurs for low spillovers; see Figure 2). Even though costs decrease with spillovers, the output expansion that occurs as a result of the lower costs increases the marginal cost of the production subsidy to the government.

4) Finally, we note that $\frac{\partial \theta_{x}}{\partial s_{c}}<0$ (see Figure 3): the cost of the innovation subsidy decreases with the production subsidy because an increase in $s_{c}$ reduces production costs, reducing the incentives for firms to invest in innovation, reducing $\theta_{x}$ (for a given level of $\left.s_{x}\right)^{8}$. Moreover, this effect is reinforced by spillovers: the innovation subsidy is very expensive for high spillovers (because $x$ is high), thus the reduction in $\theta_{x}$ in dollar terms increases with $\beta$; furthermore, $\frac{\partial s_{c}}{\partial \beta}>0$ for high $\beta$, reinforcing this effect.

We can now understand the U-shaped relationship between $s_{c}$ and $\beta$ illustrated in Figure 2. The production subsidy first decreases with $\beta$; in this range, the marginal benefits of $s_{c}$ to consumers and firms are decreasing in $\beta$, and $\frac{\partial \theta_{c}}{\partial s_{c}}$ is increasing in $\beta$. Moreover, in this range the benefits to the government from the reduction in $\theta_{x}$ are still small. For high $\beta$, however, $\frac{\partial \theta_{x}}{\partial s_{c}}$ becomes very significant, leading to an increase in the optimal production subsidy. Hence, the main reason the government increases the production subsidy with spillovers (for high spillovers) is to reduce the cost of the innovation subsidy.

The analysis of configurations 2 to 5 (shown in tables $1 \mathrm{~b}$ to $1 \mathrm{e}$ above) is similar to the above analysis. The four effects described in Figure 3 have the same signs, and bear a similar relationship to spillovers as in configuration 1. Only, in these configurations, the benefit from the reduction in $\theta_{x}$ is substantial, and dominates the other effects even for low levels of spillovers. Hence $s_{c}$

\footnotetext{
${ }^{7}$ This follows from the result that R\&D increases with spillovers (see regularity 4 below).

${ }^{8}$ This point will be shown in the next section.
} 


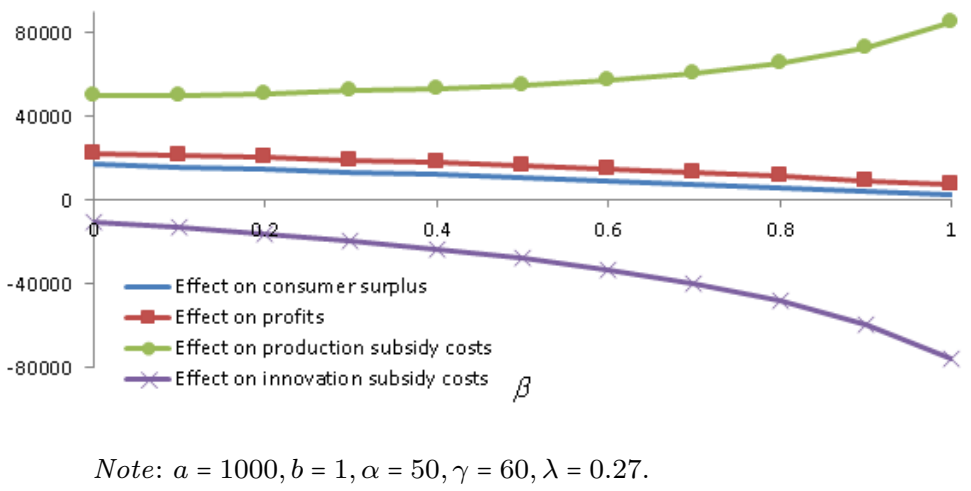

Figure 3. Marginal effects of a production subsidy.

increases monotonically with spillovers in theses cases, as described in Regularity 2.

Using the same method, we then illustrate graphically the four terms composing the f.o.c. determining $s_{x}$ (see Figure 4) from equation (11). Note that the innovation subsidy always increases with spillovers, irrespective of the configuration considered, as shown in tables 1a through 1e above.

1) and 2) The marginal benefits of $s_{x}$ to consumers and firms increase with spillovers: as $\beta$ increases, firms would like to reduce their R\&D; at the same time, the social benefit from $\mathrm{R} \& \mathrm{D}$ increases for consumers (lower prices through a stronger cost reduction because of spillovers) and for the competitor (lower costs).

3) $\frac{\partial \theta_{x}}{\partial s_{x}}$ increases steeply with spillovers: as spillovers increase, $s_{x}$ increases, and given the quadratic $\mathrm{R} \& \mathrm{D}$ costs, the cost of the innovation subsidy increases sharply.

4) Here too there are synergies between the two subsidies: $\frac{\partial \theta_{c}}{s_{x}}<0$, that is, the innovation subsidy reduces the cost of the production subsidy ${ }^{9}$.

We can now explain why the innovation subsidy increases with spillovers. As $\beta$ increases, the marginal benefits of $s_{x}$ to firms and consumers increase, and the reduction in the cost of the production subsidy increases; these benefits outweigh the steep increase in the marginal cost of the innovation subsidy with spillovers, leading to a positive relationship between $s_{x}$ and $\beta$. The optimal $s_{x}$ would increase with $\beta$ even in the absence of a production subsidy; but the effect $\frac{\partial \theta_{c}}{s_{x}}<0$ makes the optimal $s_{x}$ increase even faster with $\beta$.

Figures 3 and 4 illustrate that the marginal effects of subsidies on own and cross-subsidy costs are more important than the marginal gains of the subsidies to consumers and firms; thus it is mainly cost considerations, rather than benefit considerations, which drive the socially optimal subsidy rates.

Moreover, note (from Figure 2, and also from tables $1 \mathrm{~b}$ to $1 \mathrm{e}$ ) that for low $\beta, s_{c}>s_{x}$ : for this range of $\beta$, the underinvestment in innovation is not too severe, and the production subsidy is higher. However, for high $\beta$, the underinvestment in innovation is significant, and $s_{c}<s_{x}$. More precisely, the four effects identified in equations (10) and (11) (and illustrated in figures 3 and 4) result in a higher $s_{c}$ for low $\beta$ and a higher $s_{x}$ for high $\beta$.

\footnotetext{
${ }^{9}$ This point will be shown in the next section.
} 


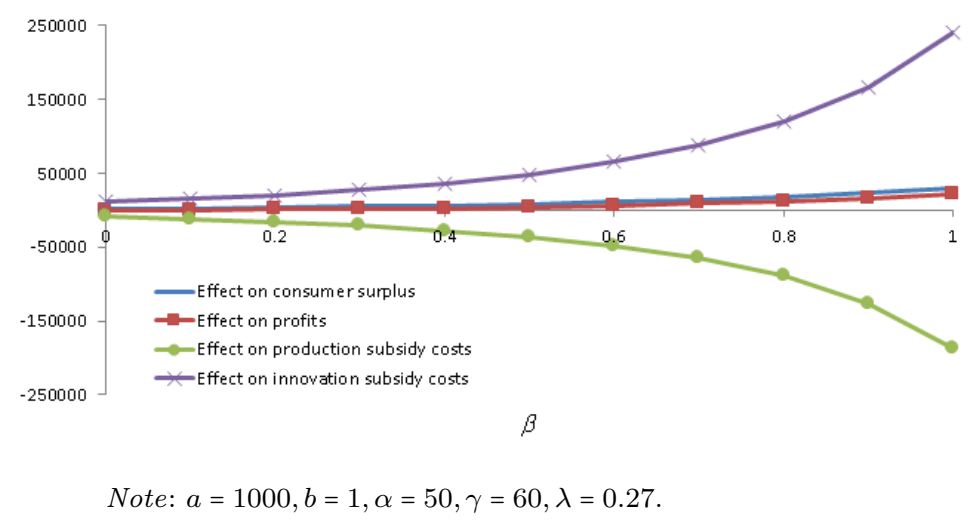

Figure 4. Marginal effects of a innovation subsidy.

Regularity 3. For low $\beta, s_{c}>s_{x}$. For high $\beta, s_{c}<s_{x}$.

This result is consistent with the results of Kesavayuth and Zikos (2013) who also find that the innovation (production) subsidy is more socially valuable when spillovers are high (low). However, in their model the government has to choose between the two types of subsidies. Moreover, here, in contrast to Leahy and Neary (1997) and Petrakis and Poyago-Theotoky (2002), it is never optimal to tax R\&D, even for low spillovers. This is because the positive production subsidy depresses $R \& D$ sufficiently that a positive $R \& D$ subsidy is always called for.

It is useful at this stage to plot equilibrium $R \& D$ as a function of spillovers. It is well know that in the absence of subsidies, innovation decreases with spillovers (d'Aspremont and Jacquemin, 1988). The innovation subsidy reverses this result. Figure 5 plots R\&D as a function of spillovers. As the figure shows, $R \& D$ increases uniformly with spillovers. This is because of the innovation subsidy, which increases with spillovers; this increase more than compensates for the decline in innovation incentives due to higher leakages. The socially optimal rate of innovation increases as spillovers increase (the positive externality on the competitor becomes more important). As spillovers increase, the government increases the innovation subsidy sufficiently to induce an increase in innovation (again, see the decomposition in Figure 4 to understand precisely why $s_{x}$ increases with $\beta$ ). Another reason why $R \& D$ increases with spillovers is that output increases with spillovers (because unit cost decreases with spillovers), increasing the value of cost reduction, inducing firms to invest more in R\&D.

Regularity 4. In the presence of production and innovation subsidies, equilibrium RED increases with spillovers.

While this result is derived in the presence of production and innovation subsidies, it can be shown that the innovation subsidy alone is sufficient to generate this positive relationship between R\&D and spillovers.

The results of this model shed light on the debate regarding the optimal degree of intellectual property protection, (here) in the presence of production and innovation subsidies. To verify whether society gains or loses from stronger IPRs, Figure 6 plots industry profits, consumer surplus, and welfare as a function of spillovers, when all variables, including $s_{c}$ and $s_{x}$, take their 


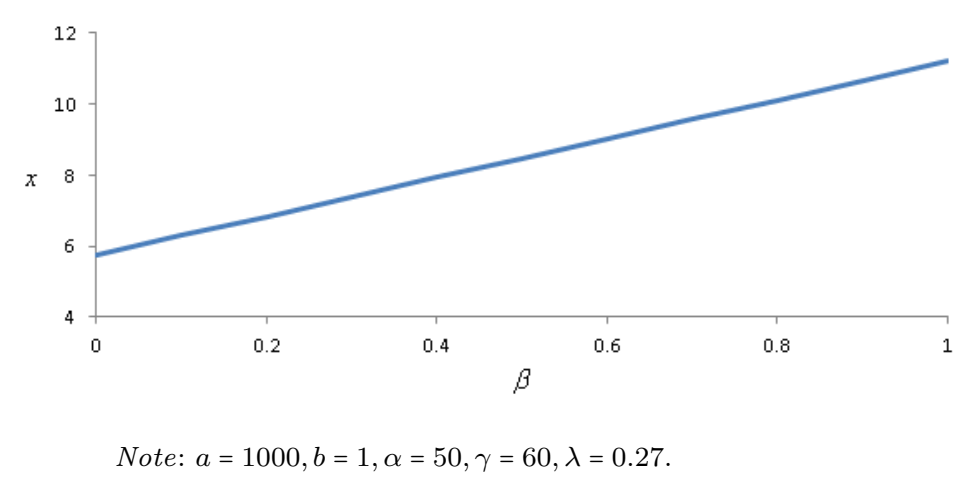

Figure 5. Effect of spillovers on equilibrium R\&D.

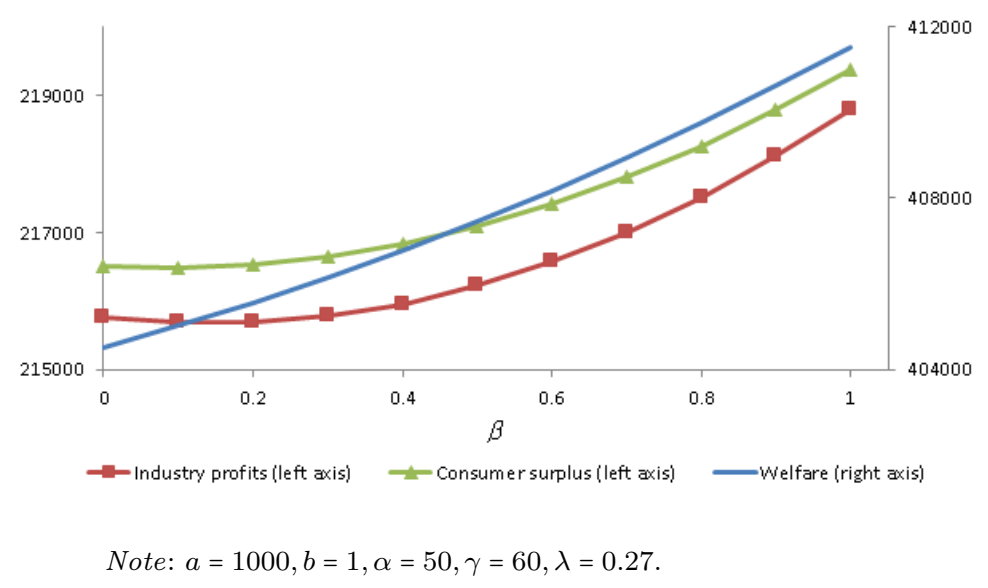

Figure 6. Marginal effects of a production subsidy.

equilibrium values. As the figure shows, consumer surplus and profits first decrease then increase with spillovers. The initial decrease is due to the decrease in $s_{c}$ for low $\beta$, which increases costs and prices. However, for moderate to high values of $\beta$, consumer surplus and profits increase with $\beta$. Over this range, $\mathrm{R} \& \mathrm{D}$ is higher (it is always increasing with $\beta$ ), and $s_{c}$ (eventually) comes to rise with $\beta$. And consumer surplus starts to rise with spillovers earlier than profits. On the other hand, welfare uniformly increases with $\beta$. Even when consumer surplus and profits are decreasing in $\beta$ (for low $\beta$ ), welfare rises with $\beta$, due to the increase in $\mathrm{R} \& \mathrm{D}$, and to the decrease in $\theta_{c}$. But all economic agents prefer very high spillovers to very low spillovers (even firms, who normally would lose from weaker IPRs) in the presence of properly chosen subsidies. This is in contrast to the result that, in the absence of subsidies, profits and welfare have an inverted-U shape with respect to spillovers; see Stepanova (2009), for example.

Figure 6 illustrates the results of configuration 1 (see Table 1a above), where the production subsidy is U-shaped with respect to spillovers. When, however, the production subsidy is monotonically increasing in spillovers, then consumer surplus and profit (as well as welfare) are always increasing in spillovers.

Regularity 5. Consumer surplus and profits are U-shaped with respect to spillovers when the production subsidy is U-shaped with respect to spillovers; they increase monotonically with spillo- 
vers when the production subsidy always increases with spillovers. Welfare always increases with spillovers. All three variables are maximized with perfect spillovers.

\section{Effects of Subsidy Rates on Subsidy Costs}

In this section we formalize the effect of subsidy rates on the cost of subsidies to the government; some of these effects were discussed above. Consider first the effect of $s_{c}$ on $\theta_{c}$. From (8), $\theta_{c}$ depends (for fixed $\lambda$ ) on $s_{c}, c$ and $y$. The increase in $s_{c}$ increases $c$ (because it reduces $x$; see regularity 1); this effect pushes $y$ down. The increase in $s_{c}$ also reduces the effective marginal cost $\left(1-s_{c}\right) c$; this effect pushes $y$ up. It is easy to verify that the positive effect of the increase in $s_{c}$ on $y$ dominates the negative effect of the decrease in $x$ on $y$, so that $\frac{\partial y}{\partial s_{c}}>0$. Thus the increase in $s_{c}$ increases both production costs and output, henceforth $\frac{\partial \theta_{c}}{s_{c}}>0$. The following equation summarizes the effect of an increase in $s_{c}$ on $\theta_{c}$ :

$$
\begin{array}{r}
\theta_{c}=(1+\lambda) s_{c}\left(c_{1} y_{1}+c_{2} y_{2}\right) . \\
\uparrow \\
\uparrow \uparrow \uparrow
\end{array}
$$

Consider next the effect of $s_{x}$ on $\theta_{x}$. From (9), $\theta_{x}$ depends (for fixed $\lambda$ and $\gamma$ ) on $s_{x}$ and $x$. As $\frac{\partial x}{\partial s_{x}}>0$, it follows that $\frac{\partial \theta_{x}}{\partial s_{x}}>0$. The following equation summarizes the effect of an increase in $s_{x}$ on $\theta_{x}$ :

$$
\begin{aligned}
& \theta_{x}=(1+\lambda) s_{x} \frac{\gamma}{2}\left(x_{1}^{2}+x_{2}^{2}\right) . \\
& \uparrow \quad \uparrow \quad \uparrow \quad \uparrow
\end{aligned}
$$

Consider now the effect of a type of subsidy on the cost of the other subsidy. An increase in $s_{x}$ reduces unit cost $c$ and increases $y$, hence the sign of $\frac{\partial \theta_{c}}{\partial s_{x}}$ is a priori ambiguous. To verify which effect dominates, we plot $\theta_{c}$ as a function of $s_{x}$. As Figure 7 shows, the relationship is negative, indicating that the decline in costs is more important than the increase in output, meaning that a higher innovation subsidy rate reduces the total cost of the production subsidy. Moreover, as Figure 7 shows $^{10}$, the decrease in $\theta_{c}$ can be substantial: when $s_{x}$ goes from 0 to $0.8, \theta_{c}$ is reduced almost by half ${ }^{11}$. Moreover, as Figure 4 shows, this effect is more pronounced for high spillovers. With high spillovers, output is higher (due to lower costs), making $\theta_{c}$ higher, making the economies from a higher $s_{x}$ more important.

The following equation summarizes the effect of an increase in $s_{x}$ on $\theta_{c}$ :

$$
\begin{gathered}
\theta_{c}=(1+\lambda) s_{c}\left(c_{1} y_{1}+c_{2} y_{2}\right) . \\
\downarrow \\
\downarrow \uparrow \uparrow \quad \downarrow \uparrow
\end{gathered}
$$

Next, consider the effect of $s_{c}$ on $\theta_{c}$. As $\frac{\partial x}{\partial s_{c}}<0$, it follows that $\frac{\partial \theta_{x}}{\partial s_{c}}<0$ : a higher production subsidy rate reduces the total cost of the innovation subsidy. As $s_{c}$ increases, production costs decrease. This reduces the incentives of firms to invest in R\&D (for a given $s_{x}$ ), reducing the

\footnotetext{
${ }^{10}$ On this figure $s_{x}$ stops at 0.8 , because for higher values of $s_{x}$ some endogenous variables (like $c$ ) become negative.

${ }^{11}$ It is important not to confuse the effect of $s_{x}$ on the marginal cost of the production subsidy, $\frac{\partial^{2} \theta_{c}}{\partial s_{c} \partial s_{x}}$, which may be positive or negative, with the effect of $s_{x}$ on the total cost of the production subsidy, $\frac{\partial \theta_{c}}{\partial s_{x}}$, which is always negative.
} 


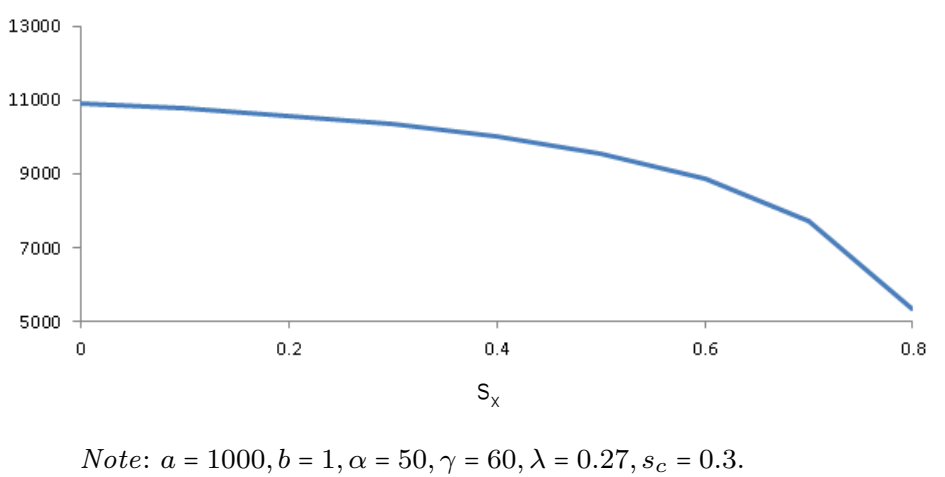

Figure 7. Cost of the production subsidy as a function of the innovation subsidy rate.

cost of $s_{x}$ to the government. Also, this effect becomes more pronounced (more negative) as $\beta$ increases (see Figure 3): a higher $\beta$ means higher $\mathrm{R} \& \mathrm{D}$ and $s_{x}$ (which translate into a higher $\theta_{x}$ ), making the savings from a higher $s_{c}$ more important. The following equation summarizes the effect of an increase in $s_{c}$ on $\theta_{x}$ :

$$
\begin{gathered}
\theta_{x}=(1+\lambda) s_{x} \frac{\gamma}{2}\left(x_{1}^{2}+x_{2}^{2}\right) . \\
\downarrow \\
\downarrow
\end{gathered}
$$

It is easy to verify that the positive own cost effect is always larger than the negative crosseffect, so that an increase in any subsidy rate always increases total subsidy costs.

Regularity 6. An increase in one subsidy rate always increases the total cost of that subsidy and total subsidy costs, and reduces the total cost of the other subsidy.

\section{Strategic Interaction Between Production and Innovation Subsidies}

It is useful to examine the strategic interaction between $s_{c}$ and $s_{x}$. Does the government view them as strategic complements or substitutes? The sign of $\frac{\partial^{2} W}{\partial s_{c} \partial s_{x}}$ is illustrated in Figure 8 for three spillover values: $\beta=0,0.4$, and 1 . This figure shows that $s_{c}$ and $s_{x}$ are more likely to be strategic complements when $s_{c}$ is low, when $s_{x}$ is high, and when $\beta$ is low.

To understand this result, from (4) we differentiate $W$ w.r.t. $s_{x}$ and $s_{c}$ :

$$
\frac{\partial^{2} W}{\partial s_{x} \partial s_{c}}=\frac{\partial^{2} W}{\partial s_{c} \partial s_{x}}=\frac{\partial^{2} C S}{\partial s_{x} \partial s_{c}}+\frac{\partial^{2} \Pi}{\partial s_{x} \partial s_{c}}-\frac{\partial^{2} \theta_{c}}{\partial s_{x} \partial s_{c}}-\frac{\partial^{2} \theta_{x}}{\partial s_{x} \partial s_{c}} .
$$

The first term, $\frac{\partial^{2} C S}{\partial s_{x} \partial s_{c}}$, is found to be negative: increases in either subsidy reduce the gain of the other subsidy to consumers, since both subsidies reduce costs and prices, and the marginal gain is lower when we start from a lower level of costs or prices. Moreover, this effect is found to be more pronounced when $s_{c}$ is low and $s_{x}$ is high. But its overall magnitude is not large enough to dominate the other terms and have a strong effect on strategic interaction.

The second term, $\frac{\partial^{2} \Pi}{\partial s_{x} \partial s_{c}}$, tends to be positive (negative) with low (high) spillovers. And its magnitude (in absolute value) increases with $s_{x}$ and decreases with $s_{c}$ : an increase in the 


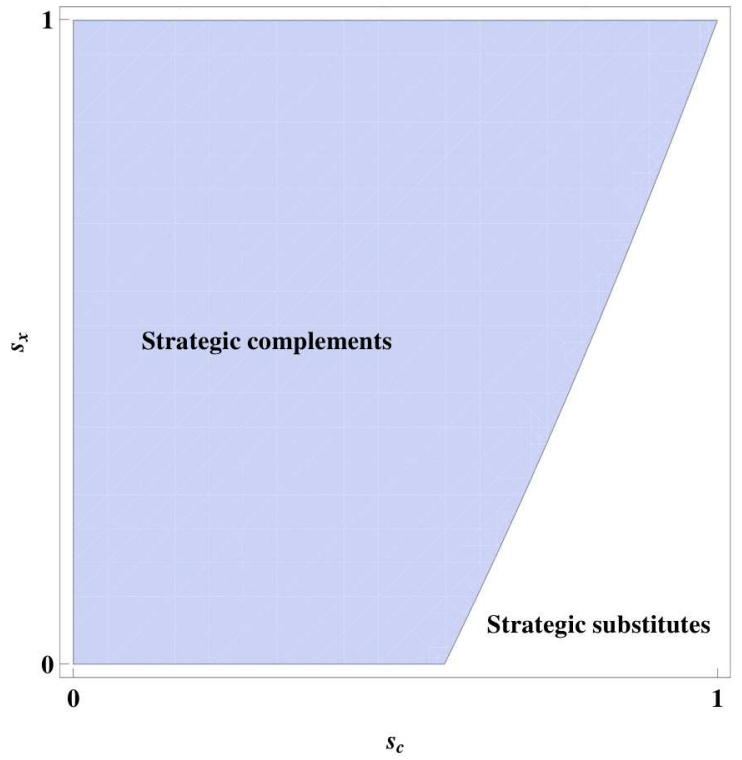

(a) Strategic interaction, $\beta=0$.

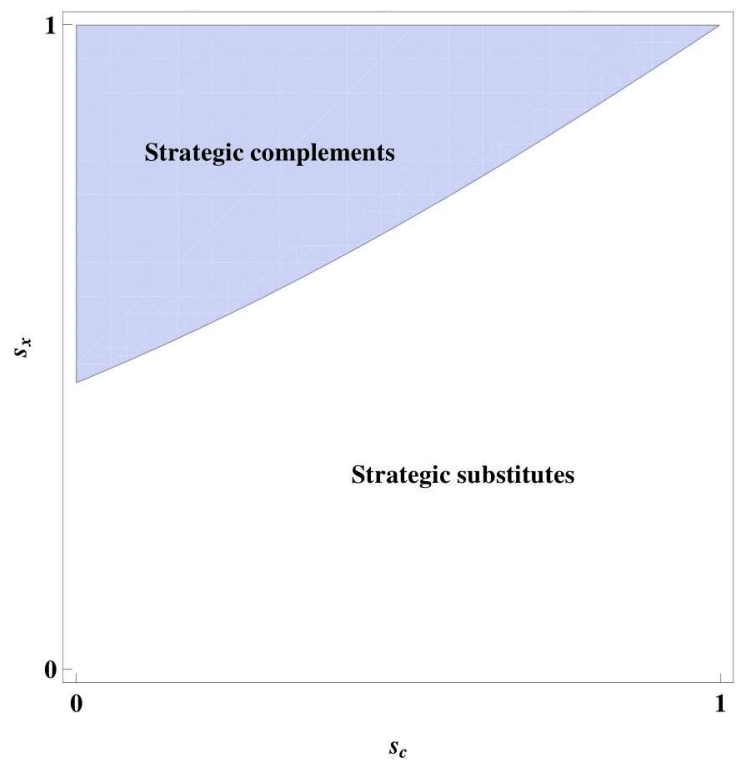

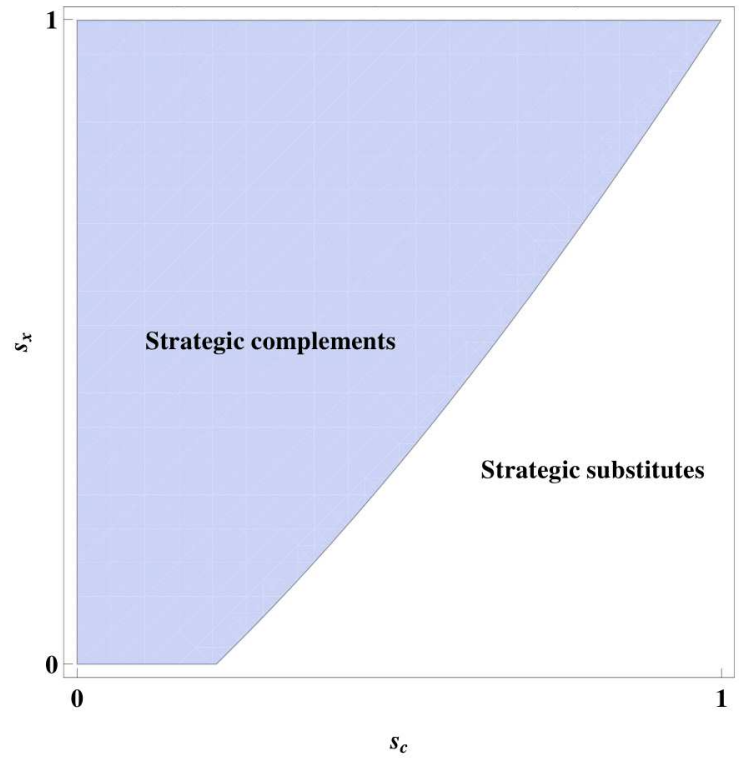

(b) Strategic interaction, $\beta=0.4$.

(c) Strategic interaction, $\beta=1$.

Note: $a=1000, b=1, \alpha=50, \gamma=60, \lambda=0.27$.

Figure 8. Strategic interaction.

innovation subsidy is most useful when $s_{c}$ is low. But its magnitude is the smallest among the four terms, and has no effect whatsoever on the sign of (12).

The third term, which can also be written as $\frac{\partial^{2} \theta_{c}}{\partial s_{c} \partial s_{x}}$, represents the effect of the innovation subsidy on the marginal cost of the production subsidy. It tends to be positive (negative) when $s_{c}$ is high (low), and its magnitude (in absolute value) increases with spillovers. When $s_{c}$ is low, an increase in $s_{x}$ reduces the marginal cost of $s_{c}$ : the increase in $s_{x}$ boosts innovation, reducing costs, and reducing the cost of $s_{c}$. However, when $s_{c}$ is high, the increase in $s_{x}$, which 
also increases output, raises the marginal cost of the production subsidy significantly (remember that $\left.\theta_{c}=(1+\lambda) s_{c}\left(c_{1} y_{1}+c_{2} y_{2}\right)\right)$. The magnitude of this term relative to the three other terms becomes critical when $s_{c}$ is high and $s_{x}$ is low; in that case it is the main factor behind strategic substitutability between $s_{c}$ and $s_{x}$.

The last term, $\frac{\partial^{2} \theta_{x}}{\partial s_{x} \partial s_{c}}$, is negative. It becomes more negative when $s_{c}$ is low, when $s_{x}$ is high, and when spillovers are low. It dominates all the other terms combined when it is large in absolute value, and is the main driver of strategic complementarity between subsidies. An increase in $s_{c}$ reduces innovation (see Figure 1), reducing the marginal cost of the innovation subsidy. When $s_{x}$ is small and $s_{c}$ is large, $x$ is small, thus the effect of $s_{c}$, while still present, is less important, and the third term above dominates.

Regularity 7. $s_{c}$ and $s_{x}$ are more likely to be strategic complements when $s_{c}$ is low, when $s_{x}$ is high, and when spillovers are low. Otherwise, they are more likely to be strategic substitutes. In equilibrium, they are always strategic complements.

The strategic interaction between production and innovation subsidies is mainly driven by cost considerations, rather than the gains to consumers or firms from those subsidies. Furthermore, even though $s_{c}$ and $s_{x}$ may be strategic complements or substitutes, in equilibrium they are always strategic complements (given the choices of $s_{c}$ and $s_{x}$ by the government).

\section{Effect of Other Parameters on the Optimal Subsidies}

In this section we study the comparative statics of the model with respect to demand and cost parameters. The results obtained here are independent of whether we consider parameters such that the production subsidy increases uniformly or is U-shaped with respect to spillovers.

Consider first the effect of the height of the inverse demand curve $(a)$ on subsidies. As Figure 9 shows, the optimal subsidies have an inverted-U shape with $a$. Initially, the subsidies grow with market size, since a larger market benefits more from lower production costs and higher R\&D (both boost output). However, as market size continues to increase, the cost of both subsidies to the government increases. First, output expands, increasing the cost of the output subsidy. Second, innovation increases with market size for given subsidies, increasing the cost of the innovation subsidy (especially with quadratic innovation costs). These cost increases induce the government to reduce the subsidy rates.

Note that while this figure suggests that $s_{c}<s_{x}$, this is just an artifact of the fact that the figure is drawn for $\beta=0.4$. If we were to draw the same figure for very low $\beta$, the overall shapes would be the same, but we would have $s_{c}>s_{x}$. This is also true for figures 10,11 and 12. The ranking of $s_{c}$ and $s_{x}$ depends solely on $\beta$, as shown in Figure 2 and tables 1a to 1e.

Figure 10 shows the relationship between the optimal subsidies and the slope of the inverse demand curve, $b$. As $b$ increases, the optimal subsidies increase. A higher $b$ means a less elastic demand, and thus a lower gain from innovation, since a given reduction in costs leads to a lesser expansion in output. Thus firms reduce their investments in $R \& D$, which reduces output and increases price. To counter these effects, the government increases production and innovation subsidies, to reduce price and increase innovation incentives (in the way increasing output). 


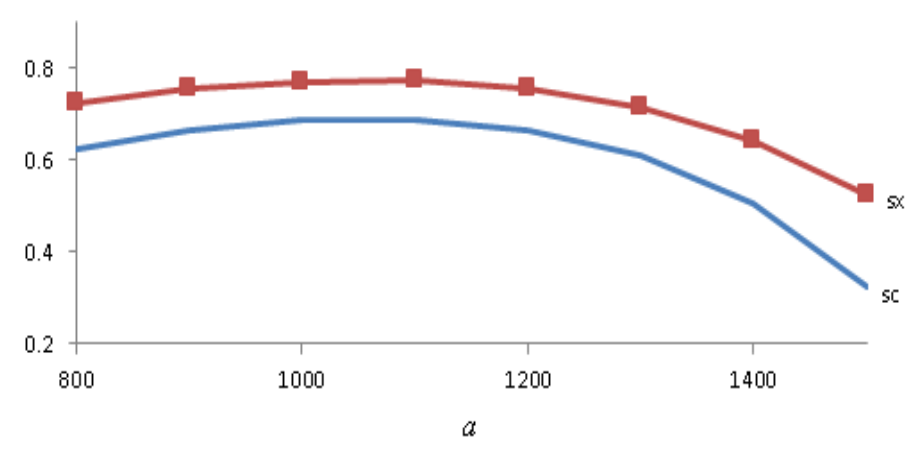

Note: $b=1, \alpha=50, \beta=0.4, \gamma=60, \lambda=0.27$.

Figure 9. Effect of demand on subsidies.

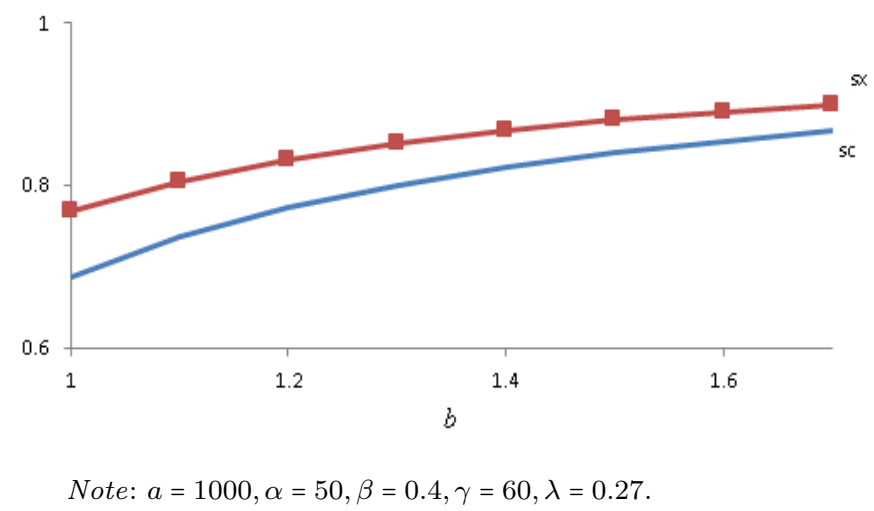

Figure 10. Effect of inverse demand slope on subsidies.

Figure 11 illustrates the relationship between the optimal subsidies and initial marginal cost: an inverted-U. For very low $\alpha$, the market is very large, subsidies are very expensive, and the government chooses low subsidy rates. As $\alpha$ increases, the market shrinks, the subsidy costs become more manageable, and the subsidies are increasing in $\alpha$. However, as $\alpha$ increases further, the market shrinks, and the gain from a dollar of production or innovation subsidies is lower. Thus, the subsidy rates are reduced. Subsidy rates are highest for "intermediate" values of $\alpha$. A similar effect was observed in Figure 9 above, where subsidy rates were highest for "intermediate" values of the demand intercept.

Kesavayuth and Zikos (2013) argue, intuitively, that higher production costs reduce the attractiveness to society of a production subsidy (relative to an innovation subsidy). Our results show that this intuition is not correct: the relationship between the optimal production subsidy (as well as the optimal innovation subsidy) and production costs is non-monotonic.

Figure 12 shows that as the cost of doing research increases, the optimal subsidies increase. A higher $\gamma$ means lower innovation, lower output and a higher price. To counter those effects, the government responds by increasing both production and innovation subsidies.

Kesavayuth and Zikos (2013) argue, intuitively, that higher research costs reduce the attractiveness to society of an innovation subsidy (relative to an output subsidy). Our results show that this intuition is not correct: higher research costs actually increase the innovation subsidy 


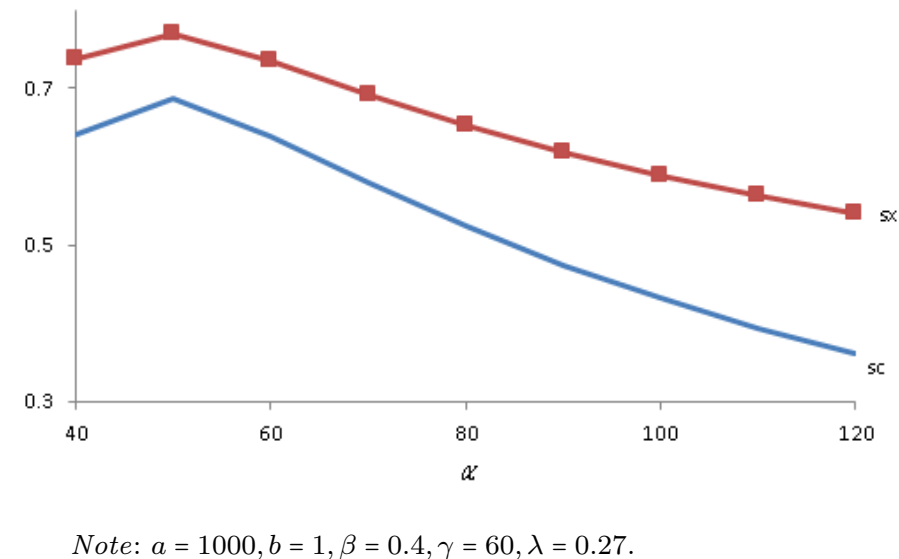

Figure 11. Effect of initial cost on subsidies.

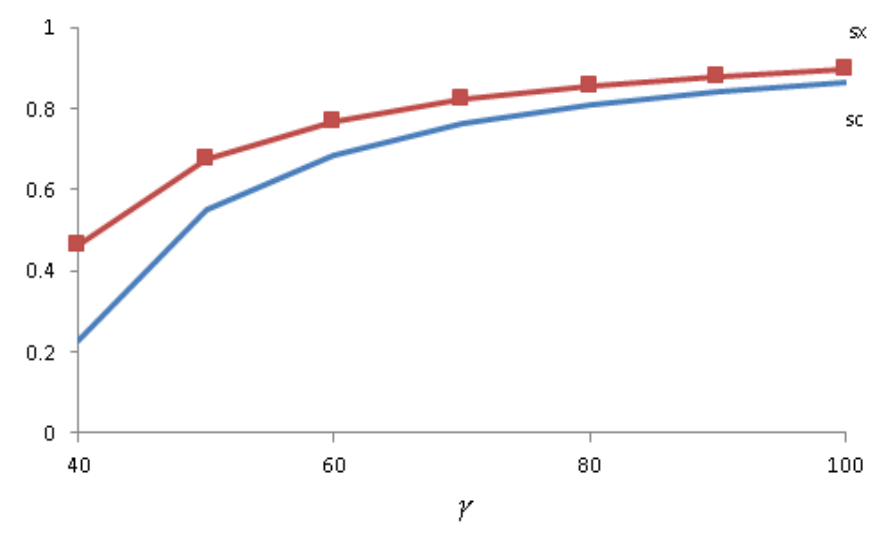

Note: $a=1000, b=1, \alpha=50, \beta=0.4, \lambda=0.27$.

Figure 12. Effect of research cost on subsidies.

rate (as well as the production subsidy rate).

Regularity 8 summarizes the results of this section.

Regularity 8. Production and innovation subsidies: i) first increase then decrease with the height of the inverse demand curve (a) and initial marginal cost ( $\alpha$ ); ii) increase with the slope of inverse demand (b) and research costs $(\gamma)$.

The two subsidies behave differently w.r.t. spillovers (see Figure 2), but behave similarly w.r.t. to the parameters mentioned in the last regularity. Moreover, not all costs are created equal: higher research costs increase both subsidies, while higher production costs first increase then decrease subsidy rates. Finally, note that $s_{c}$ and $s_{x}$ tend to move in tandem (except with $\beta$ for low $\beta$ ), reflecting the strategic complementarity (in equilibrium) between them. 


\section{A Financially Constrained Government}

In the previous analysis we considered the case where the government had enough funds to implement the socially optimal subsidy rates (given the positive shadow cost of public funds). In some cases, however, governments may have limited funds available (or legally allowed) for subsidies, and may have to underinvest in one or both subsidies relative to the socially optimal rates. In this section we ask how a financially constrained government should allocate its limited resources between production and innovation subsidies. We address this question in two ways: first by looking at the effect of changes in the shadow cost of public funds, then by explicitly introducing a budget constraint.

\subsection{The Shadow Cost of Public Funds}

Consider first the shadow cost of public funds. Figure 13 shows the effect of the shadow cost of public funds on subsidies. Figure 13a, which is drawn with $\beta=0.4$, shows that for very low $\lambda$, both subsidies take a value of 1 . For very high $\lambda$ (not shown for $s_{x}$ ), both take a value of zero. In between, both subsidies tend to lie strictly between 0 and 1 . Note that $s_{c}$ reaches zero before $s_{x}$ does. That is, when public funds are rather costly (but not extremely costly) and spillovers are significant, it is worth to subsidize innovation, but not production.

Figure 13b shows the same analysis as Figure 13a, but with $\beta=0$. The results are overall similar, except for two important differences. First, $s_{x}<s_{c}$, since the low spillover rate implies that the underinvestment in innovation is not too significant. Second, on this figure, $s_{c}$ goes to zero much more rapidly than $s_{x}$ went to zero in Figure 13a. That is, when the shadow cost of public funds is rather high (but not extremely high), it is optimal to offer no subsidies at all when spillovers are low, and to subsidize innovation only when spillovers are high. It takes a much higher shadow cost of public funds to bring the innovation subsidy to zero, than to bring the production subsidy to zero.

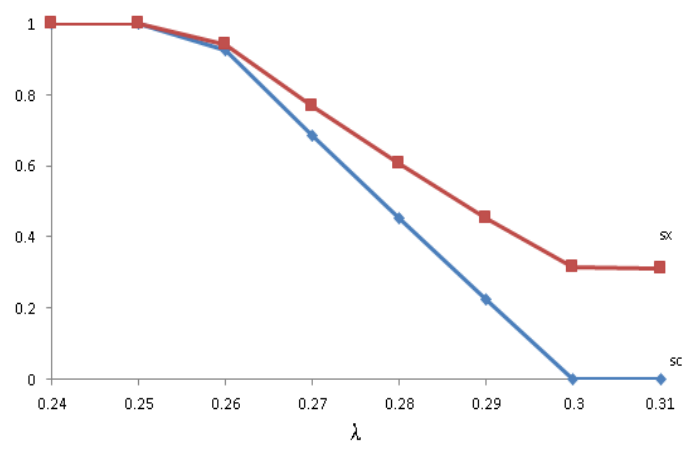

(a) $\beta=0.4$ Note: $a=1000, b=1, \alpha=50, \gamma=60$.

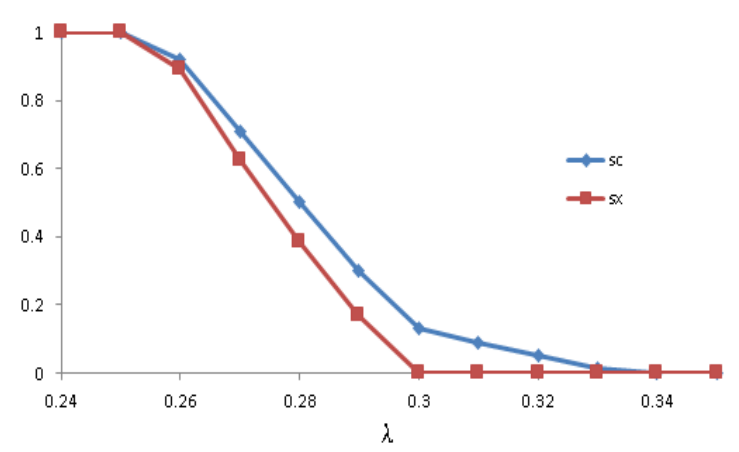

(b) $\beta=0$.

Figure 13. Effect of the shadow cost of public funds on subsidies. 


\subsection{An Explicit Budget Constraint}

We now introduce an explicit budget constraint, leaving $\lambda$ unchanged. We assume that the financially constrained government disposes of only $10 \%$ of the budget required to implement the first best subsidies (for any given parameter values). We want to inquire how the government will allocate these limited funds between production and innovation subsidies. Let $K=\theta_{c}+\theta_{x}$ represent the total cost of subsidies for a financially unconstrained government. For each spillover level, we calculate $K$, and then, at the first stage, we maximize welfare subject to the constraint:

$$
(1+\lambda)\left[s_{c}\left(c_{1} y_{1}+c_{2} y_{2}\right)+s_{x} \frac{\gamma}{2}\left(x_{1}^{2}+x_{2}^{2}\right)\right] \leq 0.1 K
$$

Let $s_{c}^{F}$ and $s_{x}^{F}$ represent optimal subsidies when the government faces the constraint (13).

Figure 14 illustrates the constrained and unconstrained subsidies. Naturally, both subsidies are lower due to the budget constraint. But the decline in $s_{c}$ is much more important than the decline in $s_{x}$. Only for very low spillovers do we have $s_{c}^{F}>s_{x}^{F}$ (the two curves cross earlier than without the financial constraint; see Figure 2). $s_{c}^{F}$ declines with spillovers, and does not have a U-shaped form as it does without the constraint (which may obtain in the absence of a budget constraint; see section 3). It reaches zero (or almost), and stays there for higher levels of spillovers. $s_{x}^{F}$, on the other hand, increases steadily with spillovers, and reaches a non-negligible proportion of its unconstrained level.

This result is consistent with our previous results: the cost of $s_{c}$ tends to be much higher than the cost of $s_{x}$ for a wide range of parameter values ${ }^{12}$, and a financially constrained government gives priority to innovation subsidies over production subsidies. Moreover, because both subsidies are below their optimal levels, the benefit of each subsidy in terms of reducing the cost of the other subsidy (see figures 3 and 4 ) is less important, making the subsidies even more expensive.

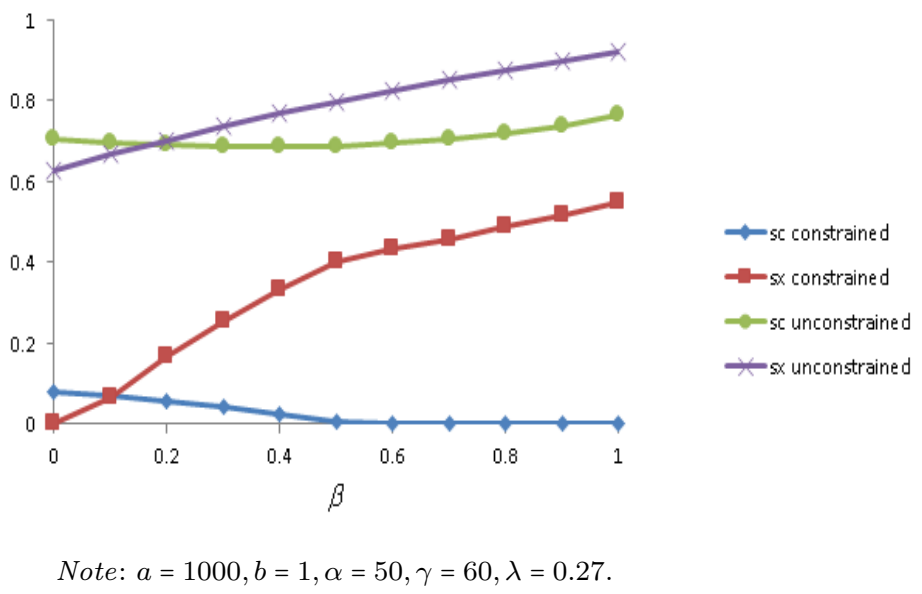

Figure 14. Optimal subsidies with and without a budget constraint.

\footnotetext{
${ }^{12}$ It can be shown, numerically, that only when $s_{c}$ gets close to zero (in the unconstrained model for high $a$ and high $\alpha$; see figures 9 and 11) do we get $\theta_{x}>\theta_{c}$. For most parameter values, even though $s_{x}>s_{c}$, we have that $\theta_{x}<\theta_{c}$. In the real world, trade agreements make it harder to provide $100 \%$ of the socially optimal production subsidy, but do not place the same limitations on innovation subsidies.
} 


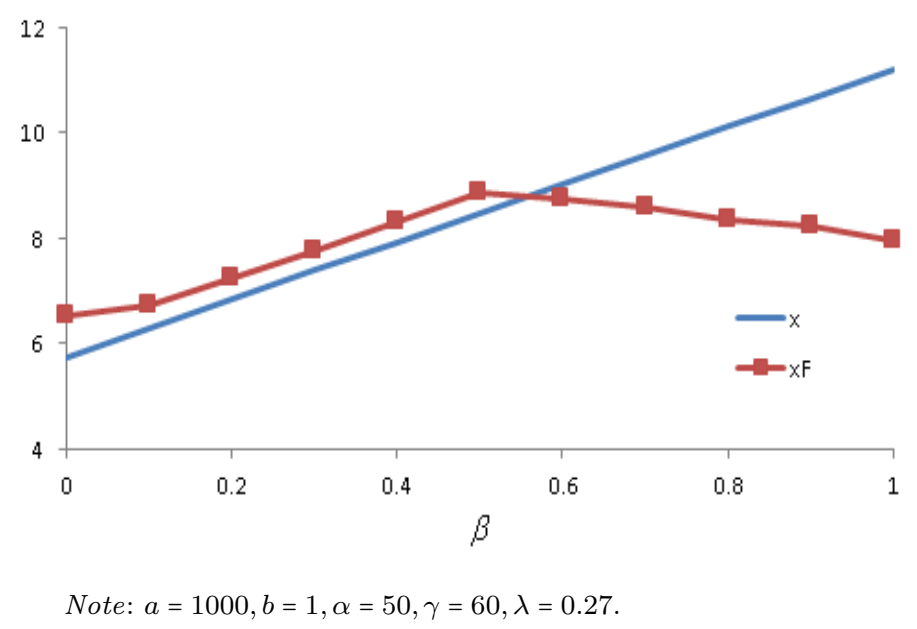

Figure 15. R\&D under a government financial constraint versus R\&D in the basic model.

Thus, to contain subsidization costs, the government prefers to raise $s_{x}$ and reduce $s_{c}$ as $\beta$ increases, except for very low $\beta$.

Regularity 9. Budgetary constraints reduce production subsidies much more than innovation subsidies, except for very low spillovers.

Figure 15 shows how innovation $\left(x_{F}\right)$ responds to spillovers with constrained subsidies. Innovation first increases with spillovers, because of the steep increase in $s_{x}^{F}$. However, as spillovers increase further, the disincentives from leakages become too important, and R\&D decreases with spillovers. Moreover, R\&D is higher (lower) than in the basic model for low (high) spillovers. As the budget constraint becomes even more strict (say, 5\%), we would expect R\&D to increase even more for low spillovers, and to decrease even more for high spillovers (relative to the basic model). Another way of reading that figure is to say that $\mathrm{R} \& \mathrm{D}$ is relatively high for low $\beta$ because of the low production subsidy, while $\mathrm{R} \& \mathrm{D}$ is low for high $\beta$ because of the (relatively) low innovation subsidy.

Regularity 10. Under a government budget constraint (with only $10 \%$ of the budget required to implement the first best subsidies), RED has an inverted-U shape with spillovers. Moreover, it exceeds RED in the basic model iff spillovers are low enough.

The results from sections 7.1 and 7.2 are in agreement that for low $\beta, s_{c}$ is more important, while for high enough $\beta, s_{x}$ is more important. But section 7.2 makes it clearer that with limited funds, priority is given to $s_{c}$ for a very narrow range of spillovers. Even in the unconstrained case, $s_{x}$ overtakes $s_{c}$ from a very low value of spillovers.

The results with a relatively high shadow cost of public funds, or with an explicit budget constraint, are in a sense more realistic than the fully unconstrained model, since governments are rarely in the comfortable financial position that would allow them to fully eradicate the effects of market power through high (and expensive) production and innovation subsidies. 


\section{A Uniform Subsidy}

In some instances the government may want to set a uniform subsidy rate that does not distinguish between production and innovation activities. This may be the case when it cannot clearly separate production costs from innovation costs, and firms may try to profit from subsidy rates differentials by classifying more expenses in the category with a higher subsidy rate.

Let everything be as in section 2, except that the government adopts a uniform subsidy rate, $s_{u}$, that applies to both production and innovation costs. Maximizing (4) subject to this constraint yields the optimal $s_{u}$, illustrated in Figure 16. First we note that $s_{u}$ increases uniformly with $\beta$ (until it reaches the maximum $s_{u}=1$ ), indicating that the desire of the social planner to finance an increasing portion of innovation activities (as $\beta$ increases) outweighs the desire to reduce the subsidization of production activities (as $\beta$ increases) when spillovers are sufficiently low.

Second, we expected $s_{u}$ to take intermediate values between $s_{c}$ and $s_{x}$. But this is not what the model says. As Figure 16 shows, for low $\beta, s_{u}<s_{c}, s_{x}$; for moderate/high $\beta, s_{u}>s_{c}, s_{x}$. For very low $\beta$, the government wishes to provide only limited incentives for innovation; this pushes $s_{u}$ down. At the same time, the government cannot fine-tune production and innovation subsidies separately (as in section 2) to exploit the fact that an increase in one type of subsidy reduces the cost of the other subsidy. To see that, Figure 17 illustrates the four terms composing the following f.o.c. (the equivalent of equations 10 and 11 above), with all variables taking their equilibrium values:

$$
\frac{\partial W}{\partial s_{u}}=\frac{\partial C S}{\partial s_{u}}+\frac{\partial \Pi}{\partial s_{u}}-\frac{\partial \theta_{c}}{\partial s_{u}}-\frac{\partial \theta_{x}}{\partial s_{u}}=0
$$

In Figure 17, the sum of the marginal benefits minus the sum of marginal costs always equals zero. As the figure shows, the marginal effect of $s_{u}$ on $\theta_{c}$ and $\theta_{x}$ is always positive. Moreover, the marginal benefit of $s_{u}$ to consumers is U-shaped with spillovers: the negative slope for low $\beta$ mimics the decline of the marginal benefit of $s_{c}$ (Figure 3), while the positive slope for high $\beta$ mimics the positive slope of the marginal benefit of $s_{x}$ (Figure 4). For firms, the marginal benefit

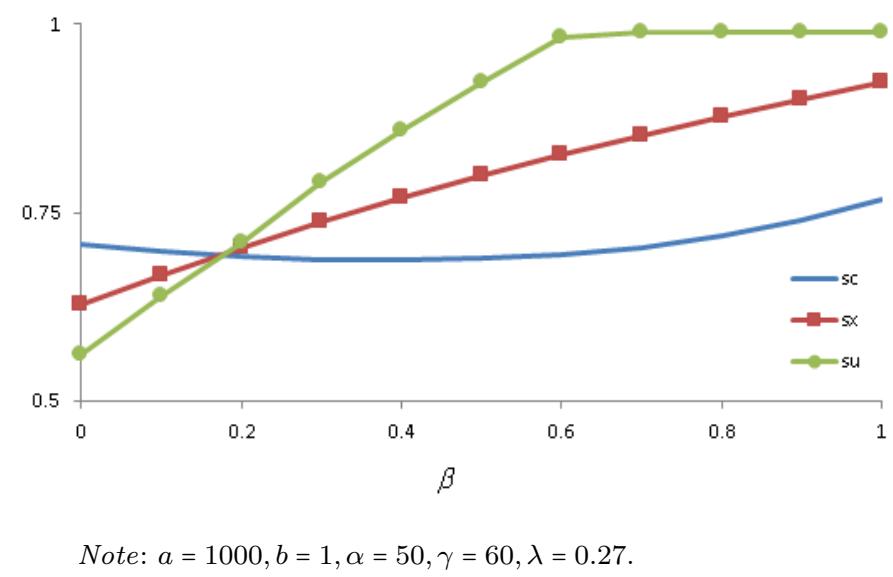

Figure 16. A uniform subsidy. 


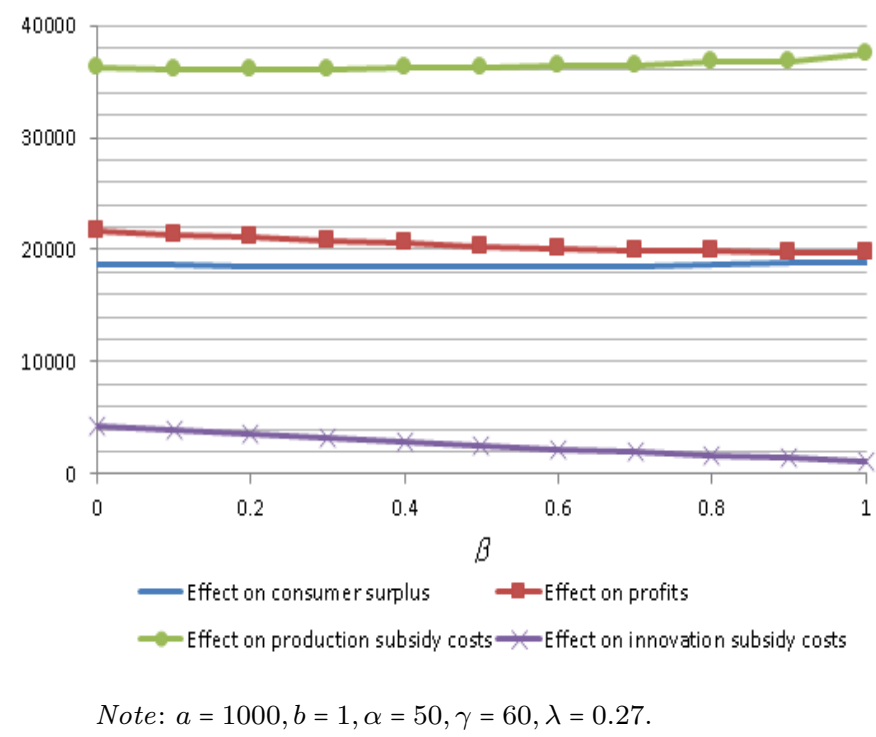

Figure 17. Marginal effects of a uniform subsidy.

of $s_{u}$ decreases with spillovers (as in Figure 3 for $s_{c}$, and differently from Figure 4, where the marginal benefit of firms from $s_{x}$ increased with $\beta$ ), indicating that, with a uniform subsidy, the effect on production incentives dominates the effect on innovation incentives.

Hence to reduce innovation incentives (for low $\beta$ ), the government is forced to also reduce production incentives. As $\beta$ increases, the government wants to increase innovation; this also forces it to increase production incentives; however, as the latter are increased, firms want to perform less R\&D; this pushes the government to increase $s_{u}$ even further. That's why $s_{u}$ very quickly overtakes $s_{c}$ and $s_{x}$. For very high $\beta$, the government sets $s_{u}$ at its maximum value (a corner solution) to compensate for the fact that the very high production incentives reduce firms' willingness to invest in $\mathrm{R} \& \mathrm{D}$, in spite of the high innovation incentives. To obtain an interior solution for very high $\beta$ would require a higher shadow cost of public funds, but to maintain comparability with the basic model we leave $\lambda$ unchanged.

To confirm that innovation incentives are lower here most of the time than in section 2, Figure 18 plots $\mathrm{R} \& \mathrm{D}$ with a uniform subsidy $\left(x_{u}\right)$, and compares it with $\mathrm{R} \& \mathrm{D}$ from section 2 . Note that $x_{u}$ decreases uniformly with spillovers, in spite of the fact that $s_{u}$ increases with spillovers. Moreover, $x_{u}$ is higher than R\&D in the basic model only for very low spillovers (because of low $\beta$ and a low $s_{c}$ ). For moderate/high spillovers, even though $s_{u}>s_{c}, s_{x}, \mathrm{R} \& \mathrm{D}$ with the uniform subsidy is smaller than R\&D in the basic model. Hence, a uniform subsidy is not a very good instrument to stimulate innovation, since most of the benefits of the innovation incentives are cancelled by the high production subsidy. Naturally, welfare also is lower with a uniform subsidy than with differentiated subsidies (and welfare with no subsidy at all is the lowest).

Regularity 11. A uniform subsidy applied to both production and innovation increases RED for low spillovers but decreases it for moderate/high spillovers. Moreover, $\frac{\partial x_{u}}{\partial \beta}<0$.

One would have thought that because the two subsidies move in tandem with most parameters 


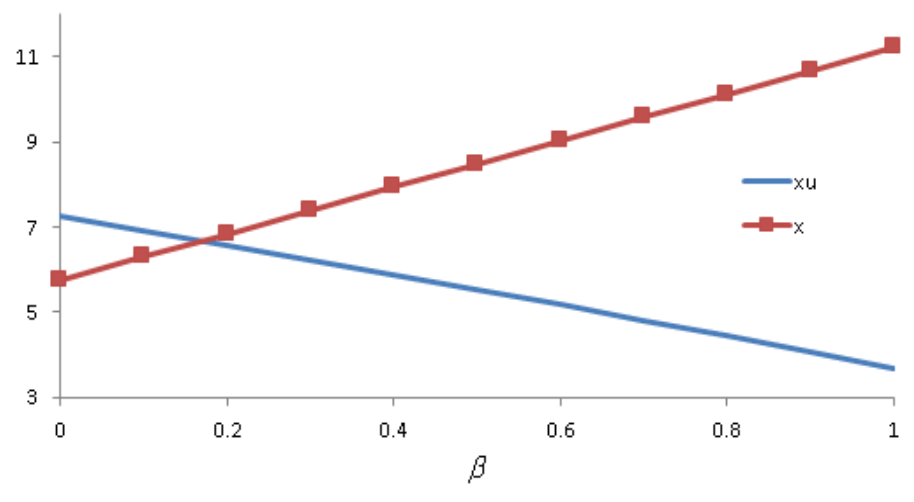

Note: $a=1000, b=1, \alpha=50, \gamma=60, \lambda=0.27$.

Figure 18. $R \& D$ with a uniform subsidy versus $R \& D$ in the basic model.

Table 2

Type of subsidies and sign of $\frac{\partial x}{\partial \beta}$.

\begin{tabular}{llc}
\hline \multicolumn{1}{c|}{ Type of subsidy(ies) } & Sign of $\frac{\partial x}{\partial \beta}$ \\
\hline \multicolumn{2}{l}{ No subsidy } & - \\
or $\quad$ Production subsidy only & \\
or $\quad$ Uniform subsidy & + \\
\hline$\quad \quad$ Innovation subsidy only & + \\
or Production and innovation subsidy & \\
or $\quad$ R\&D cooperation (with or without subsidies) & \\
\hline Production and innovation subsidies with budget constraint & + for low $\beta$ \\
& - for high $\beta$ \\
\hline
\end{tabular}

(except $\beta$ ) in the unconstrained model, and since their levels are quite close, a uniform subsidy would achieve an equilibrium which is close to the equilibrium with unconstrained subsidies. But as the results of this section show, the uniform subsidy changes radically the dynamics of subsidization, leading to much inferior outcomes.

It is interesting to note how the relationship between innovation and spillovers depends on the context. In the absence of subsidies, or with a production subsidy only, or with a uniform subsidy, R\&D decreases with spillovers. In the presence of an innovation subsidy-combined or not with a production subsidy, (or with $\mathrm{R} \& \mathrm{D}$ cooperation with or without subsidies), R\&D increases with spillovers. And under a government budget constraint, R\&D has an inverted-U shape w.r.t. spillovers. Table 2 summarizes the different cases.

\section{Conclusions}

In this paper we considered the interaction between production subsidies (to reduce production costs) and innovation subsidies (to reduce innovation costs). We allowed a benevolent government to invest in both, and identified important interactions between them. It was shown that production subsidies crowd out innovation. We also showed that providing a production subsidy reduces the cost of the innovation subsidy, and vice versa. The optimal production subsidy either increases monotonically with spillovers, or is U-shaped with spillovers, depending on exogenous 
parameters. The innovation subsidy is increasing in spillovers. The production subsidy is higher for very low spillovers, while the innovation subsidy is higher for moderate/high spillovers. In equilibrium, because of the innovation subsidy, $R \& D$ and welfare increase with spillovers. We also studied the strategic interaction between the two types of subsidies, and showed that they can be strategic complements or substitutes, but are always strategic complements in equilibrium. We analyzed how optimal subsidies change with demand and cost parameters. We studied how a financially constrained government chooses subsidies. Finally, we calculated the optimal uniform subsidy, which applies to production and innovation costs.

There is an asymmetry in the effects of the two subsidies. Production subsidies reduce innovation, but provide a benefit to consumers by reducing prices, and to the government by reducing the cost of the innovation subsidy. The innovation subsidy, on the other hand, benefits consumers and firms, and reduces the cost of the production subsidy.

The model sheds light on significant interactions between production subsidies, innovation subsidies, and spillovers. Optimal innovation and production subsidies cannot be calculated separately: governments should have integrated industrial and innovation policies, especially since each type of subsidy reduces the cost of the other subsidy. Moreover, when subsidizing production, governments have to take into account the possible crowding out of innovation. A lump sum production subsidy (or an output subsidy), while harder to justify economically and politically, avoids the disincentive that a production subsidy (which is proportional to costs) has on innovation. This crowding out effect is less important for goods for which process innovation possibilities are nil or very low.

The model studied here provides guidance as to how to improve the choices of production and innovation subsidies by governments, by taking into account factors which are currently neglected but which have a bearing on the optimal levels of those subsidies. Specifically, the model prescribes policies which are different from what is used in many countries. The model prescribes that optimal production and innovation subsidies should be calculated jointly: the optimal level of one depends on the optimal level of the other. Yet, in practice, most production and innovation subsidies programs are conceived separately, without taking into account the interaction between them. For example, many of the production subsidies given by the U.S. government (farm subsidies, oil subsidies, export subsidies, the Cash for Clunkers subsidies to auto dealers, etc.) (see Amadeo, 2019) aim solely at covering a portion of production costs; they do not take into account any innovation subsidies given to those sectors, the level of R\&D spillovers, or the possible effects on innovation of such production subsidies. The same applies to most production subsidies provided by government in other countries.

As for innovation subsidies and grants, they depend on several factors: technological and commercial risk, as in the case of Finland (Einiö, 2014), how far the project is from the market, as in Norway (Clausen, 2009), actual success/failure of the project, as in France (Guellec, 2001), the merit of the project, as with the Small Business Innovation Research program in the U.S. While these are important factors, some of the elements identified in the theoretical model above as important for determining the optimal level of the production subsidy are not taken into account in practice: the interaction with innovation subsidies, the level of R\&D spillovers 
(related to intellectual property rights protection), production costs, and the price elasticity of demand.

Moreover, the model points to several important policy considerations which should be taken into account when devising subsidies. First, in relation to intellectual property rights, a) both types of subsidies should be higher when intellectual property rights are weak; and b) weak intellectual property rights are conductive to more innovation and higher welfare levels. Second, it is often debated whether innovation subsidies simply finance innovation activities that firms would undertake anyway; the model points out that production subsidies crowd out innovation. Third, a financially constrained government should in most cases prioritize innovation subsidies over production subsidies (except for very low spillovers). Fourth, there are important synergies between subsidies, in that each type of subsidy reduces the cost of the other subsidy to the government.

\section{References}

Amadeo, K. (2019). Government Subsidies (Farm, Oil, Export, Etc) What Are the Major Federal Government Subsidies? The balance. April 8. https://www.thebalance.com/governmentsubsidies-definition-farm-oil-export-etc-3305788

Atallah, G. (2014). Conditional R\&D Subsidies. Economics of Innovation and New Technology 23(2), 179-214.

Clausen, T. (2009). Do Subsidies Have Positive Impacts on R\&D and Innovation Activities at the Firm Level? Structural Change and Economic Dynamics 20(4), 239-253.

Davis, B. (2013). China's Investments Prompt Call for new Rules. The Wall Street Journal. January 6.

d'Aspremont, C., and Jacquemin, A. (1988). Cooperative and noncooperative R\&D in duopoly with spillovers. The American Economic Review 78(5), 1133-1137.

Einiö, E. (2014). R\&D Subsidies and Company Performance: Evidence from Geographic Variation in Government Funding Based on the ERDF Population-Density Rule. The Review of Economics and Statistics 96(4), 710-728.

García-Quevedo, J. (2004). Do Public Subsidies Complement Business R\&D? A Meta-Analysis of the Econometric Evidence. Kyklos 57, 87-102.

Gössling, S., Fichert, F. and Forsyth, P. (2017). Subsidies in Aviation. Sustainability 9.1-19.

Guellec, D. (2001). Les politiques de soutien à l'innovation technologique à l'aune de la théorie économique. Économie et Prévision 150-151(4-5), 95-105.

Guellec, D., and van Pottelsberghe de la Potterie, B. (2003). The Impact of Public R\&D Expenditure on Business R\&D. Economics of Innovation and New Technology 12(3), 225-243.

Hall, J., and Laincz, C. (2012). Optimal RESD Subsidies with Heterogeneous Firms in a Dynamic Setting. WP 2012-13. Department of Economics. Drexel University.

Kesavayuth, D., and Zikos, V. (2013). R\&D versus output subsidies in mixed markets. Economics Letters 118, 293-296. 
Lahiri, S., and Ono, Y. (1999). R\&D Subsidies Under Asymmetric Duopoly: A Note. Japanese Economic Review 50(1), 104-111.

Lawrence, F. (2010). EU sugar and dairy companies largest recipients of farm subsidies. The Guardian. May 4.

Leahy, D., and Neary, J. (1997). Public policy towards R\&D in oligopolistic industries. The American Economic Review 87(4), 642-662.

Lee, E., Walker M., and Zeng, C. (2014). Do Chinese government subsidies affect firm value? Accounting, Organizations and Society 39(3), 149-169.

Lee, S., Muminov, T. and Tomaru, Y. (2017). Partial privatization and subsidization in a mixed duopoly: R\&D versus output subsidies. Hitotsubashi Journal of Economics 58(2), 163-177.

Nehring, R. (1994). Output and Input Subsidy Policy Options in Bangladesh. Journal of Agricultural Economics Research 43(2), 29-41.

Petrakis, E., and Poyago-Theotoky, J. (2002). R\&D subsidies versus R\&D cooperation in a duopoly with spillovers and pollution. Australian Economic Papers 41(1), 37-52.

Parish, R, and Mclaren, K. (1982). Relative cost-effectiveness of input and output subsidies. Australian Journal of Agricultural Economics 26(1) 1-13.

Stepanova, A. (2009). R\&D spillovers, concentration and market performance. Studies in Economics 0901. School of Economics. University of Kent.

Studwell, J. (2013). How Asia Works: Success and Failure in the World's Most Dynamic Region. London: Profile Books.

Zikos, V. (2007). A Reapraisal of the Irrelevance result in mixed duopoly: A note on R\&D competition. Economics Bulletin 12(8)1-6.

Zúñiga-Vicente, J., Alonso-Borrego, C. Forcadell, F. and Galán, J. (2014). Assessing the effect of public subsidies on firm R\&D investment: a survey. Journal of Economic Surveys 28(1), 36-67. 